\title{
Bartter-like Syndrome In a Patient Receiving Capreomycin For The Treatment Of Multidrug-Resistant Tuberculosis
}

\author{
Rusdi Zakki Aminy ${ }^{1}$, Nunuk Mardiana ${ }^{2 *}$ \\ ${ }^{1}$ Department of Internal Medicine, Faculty of Medicine, Universitas Airlangga - Dr. Soetomo General Hospital Surabaya, \\ Indonesia. \\ ${ }^{2}$ Division of Allergy and Immunology, Department of Internal Medicine, Faculty of Medicine, Universitas Airlangga - Dr. \\ Soetomo General Hospital Surabaya, Indonesia.
}

\begin{abstract}
A B S T R A C T
Bartter syndrome is inherited tubulopathy caused by mutations in several genes causing hypokalemia, hypomagnesemia, hypocalcemia with hypercalciuria, and metabolic alkalosis. Beside from inherited disorder, Bartter syndrome can be caused by the use of aminoglycosides, so it is called Bartter-like syndrome. Hypokalemia has been reported as a side effect of aminoglycosides in many studies, but Bartter-like syndrome due to aminoglycosides has only been reported in a few case reports. We report a 43 years old female patient who developed muscle weakness due to hypokalemia. We found the patient's laboratory results was consistent with Bartter syndrome. The patient had MDR-TB and received combination therapy with capreomycin for two months. We diagnosed a patient with Bartter-like syndrome due to capreomycin. Following diagnosis, we discontinued capreomycin and started potassium, magnesium and calcium therapy. After electrolyte imbalances improved, capreomycin was given three times per week and the patient was no longer experiencing the same condition.
\end{abstract}

Keywords: Bartter syndrome, hypokalemia, multidrug-resistant tuberculosis, capreomycin

Correspondence: Nunuk Mardiana

E-mail: nunuk.mardiana@yahoo.com

Article history: • Received 24 August $2020 \bullet$ Received in revised form 29 August $2020 \bullet$ Accepted 31 August 2020

\section{INTRODUCTION}

Hypokalemia is a relatively common finding in outpatients and inpatients, perhaps the most common electrolyte abnormality encountered in clinical practice. Hypokalemia is found in up to $20 \%$ of hospitalized patients. Hypokalemia can increase in-hospital mortality rate up to 10 -fold, likely due to the profound effects on arrhythmogenesis, blood pressure, and cardiovascular morbidity. Hypokalemia is often associated with an imbalance of other electrolytes, such as hypomagnesemia and hypocalcemia. Patients with hypokalemia and hypomagnesemia can be refractory to potassium replacement alone, concomitant magnesium deficiency should always be addressed with oral or parenteral repletion (Mount, 2016; Smogorzewski, et al., 2016).

Hypokalemia can be caused by spurious or pseudohypokalemia, redistribution of potassium between tissues and the extracellular fluid, non-renal loss and renal loss of potassium. Hypokalemia due to renal loss can be caused by a hereditary disorder such as Bartter syndrome and the use of drugs such as aminoglycosides (Mount, 2016).

Multidrug-resistant tuberculosis (MDR-TB) continues to be a public health crisis globally with an incidence in Indonesia about 23,000 cases in 2017 and 24,000 cases in 2018 (World Health Organization, 2019, 2018). Current therapy of MDR-TB cases use a combination of various antituberculosis drugs (ATD). One of the ATD used in the MDR-TB treatment regimen is aminoglycosides, such as capreomycin, kanamycin, and amikacin (World Health Organization, 2016). Various studies in Indonesia showed the incidence of hypokalemia in MDR-TB is 15-58\% (Anggraini, et al., 2017; Rahmawati, et al., 2016; Suparyatmo, et al., 2014). Some authors report cases of hypokalemia patients with a clinical picture resembling a Bartter syndrome due to the administration of aminoglycosides (Chothia, et al., 2018; Sharma and Sahay, 2017; Shetty, et al., 2000).

We report the case of a patient experiencing hypokalemia due to MDR-TB treatment, but we use algorithm-based diagnostic approach and manage the patient comprehensively.

\section{CASE REPORT}

A woman, 43 years old, was admitted to pulmonary ward, Dr. Soetomo General Hospital Surabaya on May 19 ${ }^{\text {th }}, 2019$ with the chief complaint of weakness.

The patient complained of weakness of both legs since a week before hospitalization, especially when the patient stood and walked. In the last two days, the weakness of the legs became worse and felt in both arms so that the patient had difficulty while doing activities. The patient had no complaints of numbness, nausea, vomiting, diarrhea, fever, and pain. The patient denied any complaints of palpitation, decreased of body weight, tremors, and heat intolerance. No history of trauma. 
History of past illness, the patient had pulmonary TB treatment in 2016 for 6 months and was declared cured. In February 2019, the patient complained of cough with productive sputum for 3 weeks without other complaints. After further examination, the patient was diagnosed with MDR-TB and had treatment since March $14^{\text {th }}, 2019$. The patient had a short-term regimen (STR) for MDRTB treatment with capreomycin $750 \mathrm{mg}$ intramuscular injection, moxifloxacin $800 \mathrm{mg}$, ethionamide $750 \mathrm{mg}$, isoniazid $600 \mathrm{mg}$, clofazimine $100 \mathrm{mg}$, ethambutol 1000 $\mathrm{mg}$, and pyrazinamide $2000 \mathrm{mg}$. No complaint of muscle weakness previously.

The physical examination revealed weak general condition, compos mentis, blood pressure 110/70 $\mathrm{mmHg}$, heart rate 92 times/minute (regular rhythm), respiratory rate 20 times/minute, axillary temperature $36.7^{\circ} \mathrm{C}, \mathrm{SpO}_{2}$ $98 \%$ on room air. The examination of the head, there was no anemia, jaundice, cyanosis, and dyspnea. In the neck, there were no lymph nodes enlargement and increased jugular venous pressure. The thoracic examination showed symmetrical chest movement, no retraction, vesicular breath sound, without rhonchi and wheezing, heart sound within normal limits, and no additional heart or gallop sounds. The abdominal examination was soft, bowel sounds within normal limits, no palpable mass, and no enlargement of the liver and spleen. The examination of the extremities, there was no edema. The motor strength of upper limb 4/4 and lower limb 4/4, without sensory deficits. The physiological reflexes found BPR $+1 /+1$, TPR $+1 /+1$, KPR $+1 /+1$, APR $+1 /+1$. Pathological reflexes such as Babinski, Chaddock, Hoffman, and Tromner were negatives.

The laboratory examination (May 19 ${ }^{\text {th }}, 2019$ ) revealed $\mathrm{Hb} 11.7 \mathrm{~g} / \mathrm{dL}$, leukocytes $12,000 / \mathrm{mm} 3$, platelets $328,000 /$ mm3, SGOT $23 \mathrm{U} / \mathrm{L}$, SGPT $17 \mathrm{U} / \mathrm{L}$, Albumin $3.6 \mathrm{~g} /$ dL, RPG $133 \mathrm{mg} / \mathrm{dL}$, BUN $10 \mathrm{mg} / \mathrm{dL}$, SCr $0.99 \mathrm{mg} /$ $\mathrm{dL}, \mathrm{Na} 139 \mathrm{mmol} / \mathrm{L}, \mathrm{K} 2.2 \mathrm{mmol} / \mathrm{L}, \mathrm{Cl} 97 \mathrm{mmol} / \mathrm{L}, \mathrm{Ca}$ $5.8 \mathrm{mg} / \mathrm{dL}$ with corrected-Ca $6.1 \mathrm{mg} / \mathrm{dL}, \mathrm{Mg} 0.9 \mathrm{mg} / \mathrm{dL}$. The ECG examination (May 19 ${ }^{\text {th }}, 2019$ at 8 am revealed PVC trigeminy. From the chest x-ray taken on May 17 th 2019, there were fibroinfiltrate in the right suprahilar and thickening of right upper pleura.

Based on the history-taking, physical examination, and laboratory results, we diagnosed the patient with MDR-TB on treatment $\left(3^{\text {rd }}\right.$ month $)+$ PVC trigeminy + hypokalemia + hypocalcemia + hypomagnesemia. We did the double intravenous line due to the patient refused the central venous catheter $(\mathrm{CVC})$ insertion. The diagnostic planning for the patient was thyroid function test, blood gas analysis, urine electrolyte, urine calcium, urine magnesium, urine urea nitrogen, urine creatinine, and urine osmolality. The therapeutic planning was high calorie high protein diet of $1,800 \mathrm{kcal} /$ day, extra fruits and vegetables, $\mathrm{KCl} 75 \mathrm{meq}$ in 1,500 cc of normal saline for 24 hours iv drip, inj. Ca gluconate $3 \times 1 \mathrm{~g}$ iv drip, $\mathrm{MgSO}_{4} 20 \% 40 \mathrm{cc}(8 \mathrm{~g})$ in 500 cc of normal saline for 24 hours iv drip, KSR $3 \times 600 \mathrm{mg}$ (8 meq), capreomycin injection was discontinued and other ATDs were continued. The monitoring planning was serial serum electrolyte, calcium, and magnesium. ECG evaluation after 8 hours of therapy showed sinus rhythm 98x/minute without PVC.

\section{The Follow Up}

On day 2 (May 20 $0^{\text {th }}, 2019$ ), the patient felt her body was still weak, with no complaints of muscle spasms, sensory deficit, and gastrointestinal symptoms. The physical examination revealed compos mentis, blood pressure 110/70 $\mathrm{mmHg}$, heart rate 77 times/minute (regular rhythm), respiratory rate 20 times/minute, axillary temperature $36.6^{\circ} \mathrm{C}, \mathrm{SpO}_{2}$ $98 \%$ on room air, and the motor strength of the upper limb $4 / 4$ and the lower limb 4/4, without sensory deficit. The laboratory examination showed $\mathrm{Na} 141 \mathrm{mmol} / \mathrm{L}, \mathrm{K} 2.5$ $\mathrm{mmol} / \mathrm{L}, \mathrm{Cl} 100 \mathrm{mmol} / \mathrm{L}, \mathrm{Ca} 5.9 \mathrm{mg} / \mathrm{dL}$ with corrected-Ca $6.1 \mathrm{mg} / \mathrm{dL}, \mathrm{Mg} 1.2 \mathrm{mg} / \mathrm{dL}$, TSH $1.53 \mathrm{uIU} / \mathrm{mL}(\mathrm{N}: 0.55-$ 4.78), FT4 1.3 ng/dL (N: 0.89-1.76). Blood gas analysis showed $\mathrm{pH} 7.5, \mathrm{pCO}_{2} 32, \mathrm{pO}_{2} 88$ (room air), $\mathrm{HCO}_{3} 30, \mathrm{Be}$ $9, \mathrm{SO}_{2} 97 \%$. The ECG examination showed sinus rhythm 80 times/minute. We diagnosed the patient with MDR-TB on treatment $\left(3^{\text {rd }}\right.$ month $)+$ post PVC trigeminy + hypokalemia + hypocalcemia + hypomagnesemia + metabolic alkalosis. The therapy was continued with the administration of $\mathrm{KCl}$ $50 \mathrm{meq}$ in 1,000 cc of normal saline for 24 hours iv drip, inj. Ca gluconate $3 \times 1 \mathrm{~g}$ iv drip, $\mathrm{MgSO}_{4} 20 \% 20 \mathrm{cc}(4 \mathrm{~g})$ in 500 cc of normal saline for 24 hours iv drip, KSR 3x600 mg.

On day 4 (May 22 $2^{\text {nd }}, 2019$ ), the patient felt her body was still weak, with no complaints of muscle spasms, sensory deficit, and gastrointestinal symptoms. The physical examination revealed compos mentis, blood pressure $110 / 70 \mathrm{mmHg}$, heart rate 90 times/minute (regular rhythm), respiratory rate 20 times/minute, axillary temperature $36.6^{\circ} \mathrm{C}, \mathrm{SpO}_{2} 98 \%$ on room air, and the motor strength of the upper limb $4 / 4$ and the lower limb 4/4, without sensory deficit. The laboratory examination showed $\mathrm{Na}$ $141 \mathrm{mmol} / \mathrm{L}, \mathrm{K} 2.7 \mathrm{mmol} / \mathrm{L}, \mathrm{Cl} 100 \mathrm{mmol} / \mathrm{L}$, Ca $6.8 \mathrm{mg} /$ dL with corrected-Ca $7.0 \mathrm{mg} / \mathrm{dL}, \mathrm{Mg} 2.7 \mathrm{mg} / \mathrm{dL}, \mathrm{P} 2.8$. The urine examination showed urine production 2,400 cc/24hour, Naurine $254 \mathrm{mmol} /$ day (105.8 mmol/L), Kurine $72 \mathrm{mmol} /$ day (30 mmol/L), Clurine $346 \mathrm{mmol} /$ day (144.2 $\mathrm{mmol} / \mathrm{L}$ ), Mgurine $377 \mathrm{mmol} /$ day (157 mg/L), Caurine $444 \mathrm{mg} /$ day $(18.5 \mathrm{mg} / \mathrm{dL} \sim 4.6 \mathrm{mmol} / \mathrm{L})$, Crurine $579 \mathrm{mg} /$ day $(24.1 \mathrm{mg} / \mathrm{dL} \sim 2.1 \mathrm{mmol} / \mathrm{L})$, urine urea nitrogen 4,896 $\mathrm{mg} /$ day $(2,040 \mathrm{mg} / \mathrm{L})$, urine osmolality $316.6 \mathrm{mOsm} / \mathrm{kg}$, plasma osmolality $291 \mathrm{mOsm} / \mathrm{kg}$, transtubular potassium gradient (TTKG) 10.2, and urine $\mathrm{Ca} / \mathrm{Cr}$ (molar ratio) 2.17. We diagnosed patient with MDR-TB on treatment $\left(3^{\text {rd }}\right.$ month $)+$ hypokalemia + hypocalcemia (improved) + hypomagnesemia (improved) + Bartter-like syndrome ec capreomycin. The therapy was continued with the administration of premix $\mathrm{KCl} 50 \mathrm{meq} / 24$ hours iv drip in 1,000 cc of normal saline, inj. Ca gluconate $3 \times 1 \mathrm{~g}$ iv drip, KSR 3x600 mg.

On day 6 (May 24 ${ }^{\text {th }}, 2019$ ), the patient felt better and had no complaints. The physical examination revealed compos mentis, blood pressure $120 / 80 \mathrm{mmHg}$, heart rate 82 times/minute (regular rhythm), respiratory rate 20 times/minute, axillary temperature $36.5^{\circ} \mathrm{C}, \mathrm{SpO}_{2} 97 \%$ on room air, and the motor strength of the upper limb $5 / 5$ and the lower limb $5 / 5$. The physiological reflexes found $+2 /+2$ in all extremities. The laboratory examination showed Na $140 \mathrm{mmol} / \mathrm{L}, \mathrm{K} 3.3 \mathrm{mmol} / \mathrm{L}, \mathrm{Cl} 100 \mathrm{mmol} / \mathrm{L}$, Ca $7.5 \mathrm{mg} / \mathrm{dL}$ with corrected-Ca $7.8 \mathrm{mg} / \mathrm{dL}, \mathrm{Mg} 1.6 \mathrm{mg} /$ $\mathrm{dL}$. We diagnosed the patient with MDR-TB on treatment $\left(3^{\text {rd }}\right.$ month $)+$ hypokalemia (improved) + hypocalcemia (improved) + hypomagnesemia (improved) + Bartter-like syndrome ec capreomycin. The patient was discharged and given KSR 3x600 mg, $\mathrm{CaCO}_{3} 3 \times 500 \mathrm{mg}(200 \mathrm{mg}$ of elemental calcium), $\mathrm{Mg}(\mathrm{OH})_{2} 3 \times 200 \mathrm{mg}(6.7 \mathrm{meq})$ for the treatment. We educated the patient to consume foods containing high potassium (fruit and vegetables), high calcium (milk, spinach, etc), and high magnesium (spinach, peanut, avocado, etc). Capreomycin was given back at a dose of $750 \mathrm{mg}$ intramuscular 3 times/week (not every day) starting the next day (May 25 $5^{\text {th }}, 2019$ ).

The patient came to the outpatient clinic three weeks 
after being discharged from the hospital (June $17^{\text {th }}, 2019$ ). The laboratory examination showed $\mathrm{Na} 141 \mathrm{mmol} / \mathrm{L}, \mathrm{K} 3.6$ $\mathrm{mmol} / \mathrm{L}, \mathrm{Cl} 100 \mathrm{mmol} / \mathrm{L}, \mathrm{Ca} 8.6 \mathrm{mg} / \mathrm{dL}$ with corrected-Ca $8.9 \mathrm{mg} / \mathrm{dL}, \mathrm{Mg} 1.9 \mathrm{mg} / \mathrm{dL}, \mathrm{BUN} 10 \mathrm{mg} / \mathrm{dL}, \mathrm{SCr} 0.8 \mathrm{mg} /$ $\mathrm{dL}$. We only educated the patient to consume foods that contain high potassium, high calcium, and high magnesium without supplement medication.

\section{DISCUSSION}

Muscle weakness is a complaint that is often found in daily practice. When dealing with patients with this symptoms, the clinician must be able to distinguish the causes whether originate from neurological, metabolic, endocrine, or muscle disorder such as myositis. The signs that lead to neurological disorders including unilateral weakness, acute progressive paraparesis, upper motor neuron sign, sensory signs or symptoms, or muscle fatigability. Myositis is suspected if having proximal weakness with tenderness or elevated CK levels. If there are no signs and symptoms above, it may be caused by metabolic or endocrine disorders such as hypokalemia, hypercalcemia, hypocortisolism or hypercortisolism, and thyroid disorders (Japp and Robertson, 2013).

The patient came with complaint of muscle weakness that occurred a week before hospitalization. There were no fever, hemiplegia, impaired speech, and sensory symptom. From physical examination, decreased motor strength was found and sensory function was within normal limits. Physiological reflexes were decreased, and no pathological reflexes were found. Laboratory examination found a decrease in serum potassium level at $2.2 \mathrm{mmol} / \mathrm{L}$. In the patient, there were no signs that lead to neurological abnormalities or myositis, so it could be concluded that the cause of muscle weakness in the patient was hypokalemia. The next step in diagnosing the patient was to find out the causes of hypokalaemia. We concluded that hypokalemia in the patient was associated with MDR-TB treatment, but we used algorithm-based approaches to diagnose the patient.

Hypokalemia can be caused by spurious or pseudohypokalemia, redistribution of potassium between tissues and the extracellular fluid, non-renal loss and renal loss of potassium. Spurious hypokalemia can occasionally result from in vitro cellular uptake of potassium after venipuncture, for example, due to profound leukocytosis in acute leukemia. Manipulation of the factors affecting internal distribution of potassium can cause hypokalemia due to redistribution of potassium between the extracellular and intracellular compartments. Endogenous insulin is rarely a cause of hypokalemia, but administered insulin is a frequent cause of iatrogenic hypokalemia. Overactivity of the endogenous sympathetic nervous system and increased catecholamine release can cause hypokalemia. Exogenous catecholamine such as $\beta 2$-agonists are powerful activators of cellular potassium uptake. Redistributive hypokalemia can also occur in the setting of hyperthyroidism that is generally called thyrotoxic periodic paralysis (TPP). Nonrenal loss of potassium commonly caused by gastrointestinal (GI) loss and very rarely integumentary loss. GI loss of potassium commonly associated with vomiting and diarrhea. Renal loss of potassium is characterized by urinary potassium more than $15 \mathrm{mmol} /$ day (Mount, 2018, 2016). Another author sets the limit of urinary potassium more than $20 \mathrm{mmol} /$ day (Tang and Linas, 2015).

The patient did not have a history of drug use which caused redistribution of potassium into the intracellular compartment such as insulin and $\beta 2$-agonists. TPP and hyperthyroidism could also be excluded due to normal thyroid function (TSH $1.53 \mathrm{uIU} / \mathrm{mL}$, FT4 $1.3 \mathrm{ng} / \mathrm{dL}$ ). Therefore, the causes of hypokalemia due to redistribution of potassium (transcellular shifts) could be excluded. The patient had a regular diet 3 times per day with enough portion, and also had no history of vomiting and diarrhea, thus GI loss of potassium could also be excluded. From the examination of 24-hour urine collected results of 72 $\mathrm{mmol} / 24$ hours potassium ( $>15$ or $20 \mathrm{mmol} / 24$ hours), it could be concluded that the cause of loss of potassium was through the kidneys.

In hypokalemia patients due to renal loss, it is necessary to evaluate the TTKG, where TTKG less than 3 is due to increased tubular flow as in the use of osmotic diuresis. In patients with TTKG more than 4 , there is an increase of distal potassium secretion from various causes. TTKG is calculated using the formula $(\mathrm{K}+$ urine/ $\mathrm{K}+$ serum $)$ / (Osmurine/Osmserum) (Mount, 2016).

The laboratory examination of the patient showed $\mathrm{K}$ +urine $30 \mathrm{mmol} / \mathrm{L}, \mathrm{K}+$ serum $\mathrm{mmol} / \mathrm{L}$, Osmurine 316 , Osmserum 291 with calculated TTKG was 10.2. It could be concluded that the patient experienced increase in distal potassium secretion.

The etiology of increased distal potassium secretion must be distinguished based on blood pressure and volume profile. In patients with high blood pressure, the possible causes are hyperaldosteronism, hypercortisolism, and Liddle's syndrome. When blood pressure is normal, it is necessary to evaluate acid-base status. Variable $\mathrm{pH}$ can be found in non-reabsorbable anions other than $\mathrm{HCO}_{3}$ such as hippurate and penicillins, also the use of aminoglycosides. Patients with metabolic acidosis may experience renal tubular acidosis (RTA) or diabetic ketoacidosis (DKA). Metabolic alkalosis can occur in several etiologies and can be distinguished using the next step of the algorithm.

Blood pressure and volume profile in the patient were normal so the next step was to evaluate the acid base status. Blood gas analysis showed metabolic alkalosis with result $\mathrm{pH} 7.5, \mathrm{pCO}^{2} 32, \mathrm{pO}_{2} 88$ (room air), $\mathrm{HCO}_{3}-30, \mathrm{Be} 9, \mathrm{SO}_{2}$ $97 \%$.

In patients with hypokalemic metabolic alkalosis, the concentration of urinary chloride less than $10 \mathrm{mmol} / \mathrm{L}$ is associated with vomiting and chloride-losing diarrhea, while the concentration of urinary chloride more than 20 $\mathrm{mmol} / \mathrm{L}$ is associated with the use of diuretics and inherited tubulopathies, such as Bartter syndrome and Gitelman syndrome. The urinary calcium/creatinine ratio $(\mathrm{UCa} /$ $\mathrm{Cr}$ ) is important to distinguish some of these etiologies, where $\mathrm{UCa} / \mathrm{Cr}>0.2$ is caused by loop diuretic and Bartter syndrome, whereas $\mathrm{UCa} / \mathrm{Cr}<0.15$ is caused by thiazide diuretic and Gitelman syndrome (Mount, 2016; Tang and Linas, 2015). The clinical approach in patients with hypokalemia, especially as a result of renal loss, can follow the algorithm in Figure 1 (appendix).

In the patient, laboratory results showed urinary $\mathrm{Cl} 346$ $\mathrm{mmol} /$ day or $144 \mathrm{mmol} / \mathrm{L}$ (>10 $\mathrm{mmol} /$ day), urinary $\mathrm{Ca} 4.6 \mathrm{mmol} / \mathrm{L}$, and urinary $\mathrm{Cr} 2.1 \mathrm{mmol} / \mathrm{L}$, thus we got the results of $\mathrm{UCa} / \mathrm{Cr} 2.17$. Based on the algorithm, hypokalemia in the patient was caused by loop diuretic or Bartter syndrome. The use of diuretics could be easily excluded because there was no such history in the patient.

Bartter syndrome (BS) is inherited tubulopathy in an autosomal recessive mode. $\mathrm{BS}$ is caused by mutations in the SLC12A1, KCNJ1, ClC-Kb, BSND, ClC-Ka, ClC-Kb, and 
CaSR gene depending on Bartter's syndrome types I to V. In patients with BS, there is a loss of the transport functions of the thick ascending limb (TAL) of the loop of Henle. Symptoms of classic BS often occur at early childhood, but patients can present at any age until adolescence, with an initial history of polyuria and polydipsia, followed by growth retardation if the diagnosis and treatment were delayed. Gitelman syndrome (GS) is another inherited tubulopathy that is caused by mutations in the SLC12A3 gene. In patients with GS, there is a loss of the transport functions of the distal convoluted tubule (DST). GS is very often asymptomatic. If symptoms occur, this is usually after six years old but the condition is often diagnosed in adolescents or adults. GS is a much more common cause of hypokalemia than Bartter's syndrome. Both BS and GS can cause hypomagnesemia. To distinguish between BS and $\mathrm{GS}$, urine $\mathrm{Ca} / \mathrm{Cr}$ ratio $(\mathrm{UCa} / \mathrm{Cr})$ can be used. However, the distinction between BS and GS is not always that simple because of phenotypic variances (Al Shibli and Narchi, 2015; Mount, 2016).

Based on the algorithm discussed earlier, it could be concluded that the patient experienced hypokalemia due to Bartter syndrome. Hypomagnesemia and hypocalcemia in the patient supported the diagnosis of BS, but the patient did not experience polyuria, polydipsia, and growth retardation, with onset occurring in adult, thus against the diagnosis of BS. Genetic testing was needed to establish the diagnosis, but it was not performed because of limited facilities and costs. However, it should be noted that the patient was MDR-TB patient who were on treatment using capreomycin, moxifloxacin, ethionamide, isoniazid, clofazimine, ethambutol, and pyrazinamide (short term regimen). Thus, we needed to consider that the conditions that occured in this patient were secondary to the drugs.

Aminoglycosides cause a syndrome of renal potassium and magnesium wasting with hypomagnesemia, hypokalemia, hypocalcemia, and tetany. Intracellular accumulation of aminoglycosides results in tubular functional alteration of cell membrane transporters. All aminoglycosides in clinical use have been implicated, including gentamicin, tobramycin, amikacin, kanamycin, and capreomycin (Pazhayattil and Shirali, 2014; Smogorzewski, et al., 2016). Kanamycin and capreomycin currently become the first line of treatment for MDRTB. A retrospective study in Peru showed that $31 \%$ of patients undergoing MDR-TB treatment experienced hypokalemia with mean serum potassium of $2.85 \mathrm{mmol} / \mathrm{L}$. Hypomagnesemia occurs in $16 \%$ of patients, with most occurring simultaneously with hypokalemia (Shin et al., 2004). There are several studies to determine the incidence of hypokalemia in patients receiving MDRTB treatment in Indonesia. In Hasan Sadikin Hospital Bandung, hypokalemia occurs in $50 \%$ of 133 patients receiving kanamycin and capreomycin (Rahmawati, et al., 2016). In Moewardi Hospital Surakarta, hypokalemia occurs in $14.7 \%$ of 34 patients after receiving two months of kanamycin (Suparyatmo, et al., 2014). In Persahabatan Hospital Jakarta, hypokalemia occurs in $57.9 \%$ of 121 patients after receiving two months of kanamycin and capreomycin (Anggraini, et al., 2017).

There are several case reports where the administration of aminoglycoside causes hypokalemic metabolic alkalosis and hypomagnesemia resembling Bartter syndrome, thus it is called Bartter-like syndrome. Shetty, et al. (2000) reported Bartter-like syndrome in two patients who received gentamycin. Sharma and Sahay (2017) reported
Bartter-like syndrome in patients who received two months of capreomycin. Chothia, et al. (2018) reported Bartterlike syndrome in a total of three patients who received 1.5 to 3 months of kanamycin therapy. This condition is due to a gain of function mutation in the calcium-sensing receptor (CaSR) in the TAL. Activation of the CaSR receptor by aminoglycosides leads to inhibition of the luminal potassium channels in the TAL. Aminoglycosideinduced impaired mitochondrial protein synthesis and ATP generation have been hypothesized to be the cause of diffuse renal tubular dysfunction (Hung, et al., 2006).

Based on the algorithm for hypokalemia, we diagnosed the patient with Bartter syndrome with a history of administration of capreomycin for two months, thus we concluded that the patient experienced Bartter-like syndrome due to capreomycin as described in the literatures and previous case reports. The possibility of the patient suffering from true Bartter syndrome and also Gitelman syndrome actually could not be excluded because genetic testing was not performed on the patient.

The goals of therapy in hypokalemia are to prevent life threatening conditions (e.g., diaphragmatic weakness, rhabdomyolysis, and cardiac arrhythmias), replace $\mathrm{K}+$ deficit, diagnose and correct the underlying cause. The urgency of therapy depends on the severity of hypokalemia, associated conditions and settings, and the rate of decline in plasma $\mathrm{K}+$. In the absence of abnormal $\mathrm{K}+$ redistribution, the total deficit correlates with serum $\mathrm{K}+$, it drops by approximately $0.27 \mathrm{mmol} / \mathrm{L}$ for every $100-\mathrm{mmol}$ reduction in total body stores. Loss of 400 to $800 \mathrm{mmol}$ of body $\mathrm{K}+$ results in a reduction in serum $\mathrm{K}+$ by approximately $2.0 \mathrm{mmol} / \mathrm{L}$. These parameters can be used to estimate replacement goals. Parenteral (intravenous) $\mathrm{K}+$ administration should be limited to the patients who are unable to use the enteral route or when the patients are experiencing associated signs and symptoms. However, rapid correction of hypokalemia through oral supplementation is possible. Serum $\mathrm{K}+$ can be increased by 1 to $1.4 \mathrm{mmol} / \mathrm{L}$ in 60 to 90 minutes following the oral intake of $75 \mathrm{mmol}$ of $\mathrm{K}$. The usual intravenous dose is 20 to $40 \mathrm{mmol}$ of $\mathrm{KCl}$ in $1 \mathrm{~L}$ of vehicle solution. As a general rule, and to avoid venous pain, irritation, and sclerosis, concentrations of more than $60 \mathrm{mmol} / \mathrm{L}$ should not be given through a peripheral vein. Although the recommended rate of administration is 10 to $20 \mathrm{mmol} /$ hour, rates of 40 to 100 $\mathrm{mmol} /$ hour or even higher (for a short period) have been used in patients with life-threatening conditions (Mount, 2016).

Hypomagnesemia may cause symptoms and signs of disordered cardiac, neuromuscular, and central nervous system function. It is also associated with an imbalance of other electrolytes, such as potassium and calcium. Patients with hypokalemia and hypomagnesemia can be refractory to potassium replacement alone, concomitant magnesium deficiency should always be addressed with oral or parenteral repletion. The importance of treating asymptomatic magnesium deficiency remains controversial. Given the clinical manifestations, it seems prudent to replete all magnesium-deficient patients with a significant underlying cardiac or seizure disorder, patients with concurrent severe hypocalcemia or hypokalemia, and patients with isolated asymptomatic hypomagnesemia, if it is severe $(<1.4 \mathrm{mg} / \mathrm{dL})$. In a patient who is actively seizing or who has a cardiac arrhythmia, 8 to 16 meq (1 to $2 \mathrm{~g}$ ) may be administered iv over a 2- to 4-minute period, otherwise a slower rate of repletion is safer. A simple regimen for 
non-emergency magnesium repletion is to administer 64 meq $(8 \mathrm{~g})$ of $\mathrm{MgSO}_{4}$ over the first 24 hours and then 32 meq $(4 \mathrm{~g})$ daily for the next 2 to 6 days. It is important to remember that serum magnesium levels rise early, whereas intracellular stores take longer to replete, so magnesium repletion should continue for at least 1 to 2 days after the serum magnesium level normalizes. In patients with renal magnesium wasting, additional magnesium may be needed to replace ongoing losses (Smogorzewski, et al., 2016).

Acute hypocalcemia can result in severe clinical symptoms that need rapid correction, whereas chronic hypocalcemia may be an asymptomatic laboratory finding.

The classic symptoms of hypocalcemia include neuromuscular excitability in the form of numbness, circumoral tingling, feeling of pins and needles in the feet and hands, muscle cramps, carpopedal spasms, laryngeal stridor, and frank tetany. From physical examination, Chvostek's sign and Trousseau's sign may also be found. The treatment of hypocalcemia depends on speed of onset and the severity of clinical and laboratory features. Oral calcium supplementation may be sufficient treatment for mild hypocalcemia. Patients with acute and severe symptomatic hypocalcemia $(\mathrm{Ca}$ level $<$

7 to $7.5 \mathrm{mg} / \mathrm{dL}$; ionized $\mathrm{Ca} 2^{+}<0.8 \mathrm{mmol} / \mathrm{L}$ ) should be treated promptly with intravenous calcium. The preferred calcium salt is calcium gluconate $(10 \mathrm{~mL}$ of $10 \%$ calcium gluconate contains $93 \mathrm{mg}$ of elemental calcium). Initially, 1 to $2 \mathrm{~g}$ of iv calcium gluconate in $50 \mathrm{~mL}$ of $5 \%$ dextrose is given over a period of 10 to 20 minutes, followed by slow infusion at a rate of 0.3 to $1.0 \mathrm{mg}$ elemental $\mathrm{Ca} / \mathrm{kg} /$ hr. Moderate asymptomatic hypocalcemia (ionized $\mathrm{Ca} 2^{+}>$ $0.8 \mathrm{mmol} / \mathrm{L}$ ) can be treated by repeated doses of 1 to $2 \mathrm{~g}$ calcium gluconate IV every 4 hours, without continuous infusion (Smogorzewski, et al., 2016).

Based on endTB guidelines, all aminoglycoside drugs used in TB therapy, including capreomycin, kanamycin, amikacin, and streptomycin can cause hypokalemia and hypomagnesemia. In mild (3.0-3.4 mmol/L) and moderate hypokalemia (2.5-2.9 $\mathrm{mmol} / \mathrm{L})$, ATD injection can be continued and replacement of potassium using oral preparations. In severe hypokalemia (2.0-2.4 $\mathrm{mmol} / \mathrm{L})$, ATD should be discontinued, whereas in life threatening hypokalemia $(<2.0 \mathrm{mmol} / \mathrm{L})$, ATD must be discontinued. Replacement of potassium in both conditions must use intravenous potassium combined with oral preparations. Magnesium replacement in cases of mild (0.6-0.7 mmol/L) and moderate hypomagnesemia $(0.45-0.59 \mathrm{mmol} / \mathrm{L})$ can use oral preparations, whereas in severe $(0.3-0.44 \mathrm{mmol} / \mathrm{L})$ and threatening life hypomagnesemia $(<0.3 \mathrm{mmol} / \mathrm{L})$, must use intravenous magnesium combined with oral preparations (endTB Consortium, 2018).

The patient experienced severe hypokalemia $(2.2$ $\mathrm{mmol} / \mathrm{L})$, severe hypomagnesemia $(0.9 \mathrm{mg} / \mathrm{dL}$ equivalent to $0.37 \mathrm{mmol} / \mathrm{L}$ ), and hypocalcemia (corrected-Ca 6.1 $\mathrm{mg} / \mathrm{dL}$ ). Replacement of potassium using intravenous $\mathrm{KCl} 75 \mathrm{meq} / 24$ hours, followed by intravenous $\mathrm{KCl}$ 50 meq / 24 hours combination with oral KSR 3x600 mg. Magnesium replacement using intravenous $\mathrm{MgSO}_{4}$ $8 \mathrm{~g} / 24$ hours, followed by intravenous $\mathrm{MgSO}_{4} 4 \mathrm{~g} / 24$ hours. Replacement of calcium using Ca-gluconate $3 \times 1$ $\mathrm{g}$ intravenous drip. Electrolyte imbalance in the patient improved slowly. Capreomycin was initially discontinued, but after electrolyte imbalance improved, it began to be given 3 times / week (not every day). When discharged, the patient received supplementation therapies with oral potassium, magnesium, and calcium.

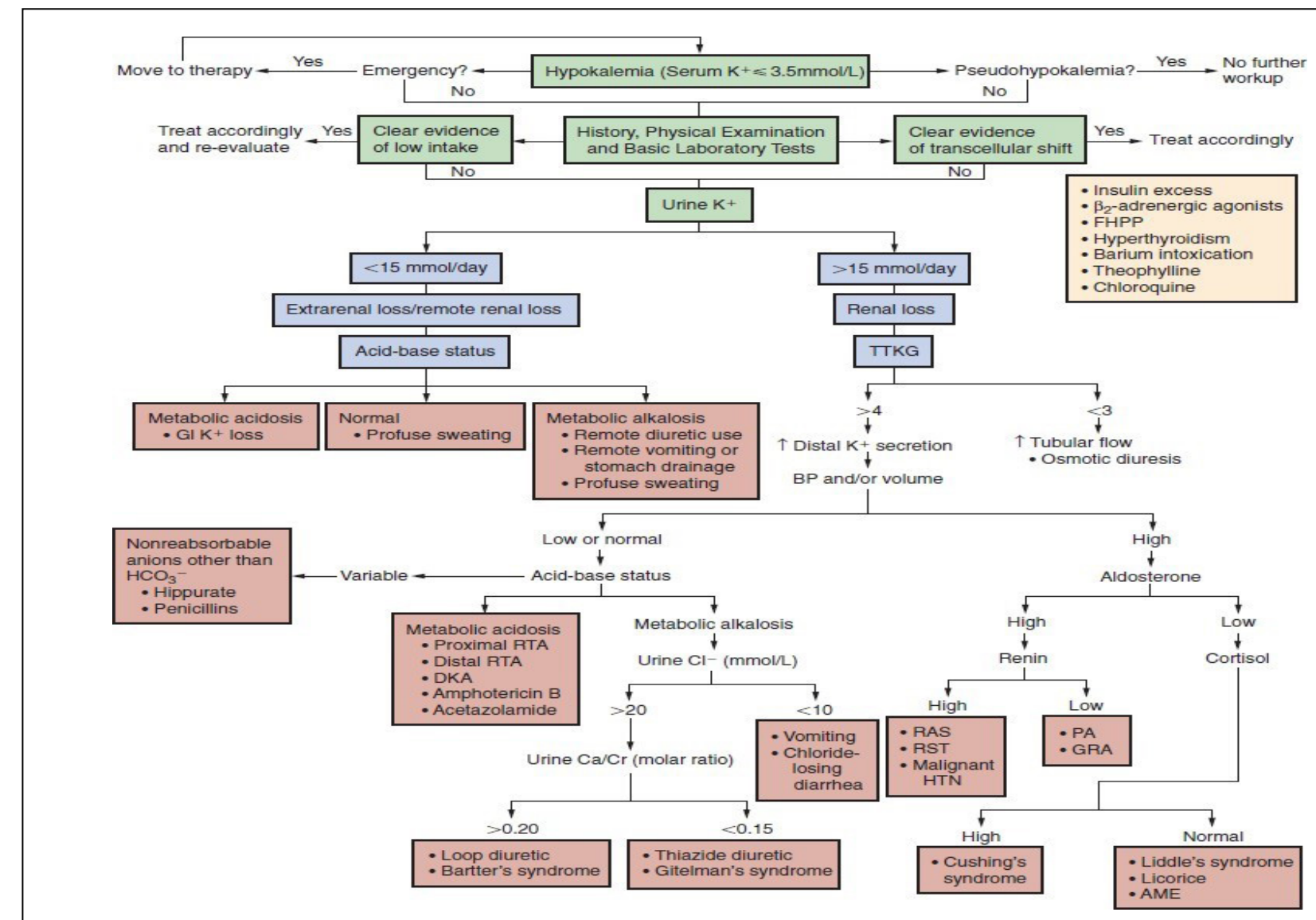

Figure 1. The clinical approach to hypokalemia (Source: Brenner \& Rector's The Kidney 10th Edition) 


\section{CONCLUSION}

It had been reported that a 43-year-old woman developed hypokalemia, hypomagnesemia, hypocalcemia with hypercalciuria, and metabolic alkalosis mimicking Bartter syndrome due to the administration of capreomycin for two months for MDR-TB treatment. True Bartter syndrome and Gitelman syndrome still cannot be excluded because genetic testing was not performed. The patient received intravenous replacement therapy of potassium, magnesium, and calcium, and temporary cessation of capreomycin. After electrolyte imbalances improved, capreomycin was given 3 times/week, and the patient received supplementation therapies with oral potassium, magnesium, and calcium..

\section{CONFLICT OF INTEREST}

The author declare there is no conflict of interest of this study.

\section{REFERENCES}

Al Shibli, A., Narchi, H., 2015. Bartter and Gitelman syndromes: Spectrum of clinical manifestations caused by different mutations. World J. Methodol. 5, 55-61.

Anggraini, D.H., Isbaniah, F., Burhan, E., 2017. Hypokalemia Among Multidrugs Resistant Tuberculosis Patients. Respirology 22, 216-217.

Chothia, M.Y., Esser, J.H., de Vries, N., Davids, M.R., 2018. Bartter-like syndrome caused by kanamycin during therapy for multidrug-resistant Mycobacterium tuberculosis. African J. Nephrol. 21, 16-19.

endTB Consortium, 2018. endTB Clinical and Programmatic Guide for Patient Management with New TB Drugs. Version 4.0.

Hung, C.C., Guh, J.Y., Kuo, M.C., Lai, Y.H., Chen, H.C., 2006. Gentamicin-induced diffuse renal tubular dysfunction. Nephrol. Dial. Transplant. 21, 547-548.

Japp, A.G., Robertson, C., 2013. Macleod's Clinical Diagnosis. Elsevier, Edinburgh. Mount, D.B., 2018. Fluid and Electrolyte Disturbances, in: Jameson, J.L., Kasper,

D.L., Longo, D.L., Fauci, A.S., Hauser, S.L., Loscalzo, J. (Eds.), Harrison's Principles of Internal Medicine 20th Edition. Mc Graw-Hill Education, New York, pp. 295-312.

Mount, D.B., 2016. Disorders of Potassium Balance, in: Skorecki, K., Chertow, G.M., Marsden, P.A., Taal, M.W., Yu, A.S.L. (Eds.), Brenner \& Rector's The Kidney 10th Edition. Elsevier, Philadelphia, pp. 559-599.
Pazhayattil, G.S., Shirali, A.C., 2014. Drug-induced impairment of renal function. Int.J. Nephrol. Renovasc. Dis. 7, 457-68.

Rahmawati, R.N., Pranggono, E.H., Ruslami, R., 2016. Clinical Characteristics and Side Effects of Multidrug Resistant Tuberculosis Therapy at Top Referral Hospital West Java Indonesia. Althea Med. J. 3, 526-32.

Sharma, P., Sahay, R.N., 2017. Unusual Complication of Multidrug Resistant Tuberculosis. Case Reports Nephrol. 2017, 1-3.

Shetty, A.K., Rogers, N.L., Mannick, E.E., Aviles, D.H., 2000. Syndrome of Hypokalemic Metabolic Alkalosis and Hypomagnesemia Associated with Gentamicin Therapy: Case Reports. Clin. Pediatr. (Phila). 39, 529-533.

Shin, S., Furin, J., Alcántara, F., Hyson, A., Joseph, K., Sánchez, E., Rich, M., 2004. Hypokalemia Among Patients Receiving Treatment for Multidrug-Resistant Tuberculosis. Chest 125, 974-980.

Smogorzewski, M.J., Stubbs, J.R., Yu, A.S.L., 2016. Disorders of Calcium, Magnesium, and Phosphate Balance, in: Skorecki, K., Chertow, G.M., Marsden, P.A., Taal, M.W., Yu, A.S.L. (Eds.), Brenner \& Rector's The Kidney 10th Edition. Elsevier, Philadelphia, pp. 601-634.

Suparyatmo, J.B., AS, B.R., Harsini, Sukma, 2014. Kalium di Multidrug Resistance Tuberculosis dengan Pengobatan Kanamisin. Indones. Hournal Clin. Pathol. Med. Lab. 21, 16-19.

Tang, J., Linas, S.L., 2015. The Patient with Hypokalemia or Hyperkalemia, in: Schrier, R.W. (Ed.), Manual of Nephrology 8th Edition. Wolters Kluwer Health, Philadelphia, pp. $48-60$.

World Health Organization, 2019. Global Tuberculosis Report 2019. Geneva, Switzerland.

World Health Organization, 2018. Global Tuberculosis Report 2018. Geneva, Switzerland.

World Health Organization, 2016. WHO treatment guidelines for drugresistant tuberculosis, 2016 update. Geneva, Switzerland. 